\title{
Perbandingan hasil pengukuran pada citra Cone Beam Computed Tomography $(C B C T)$ dengan objek sesungguhnya
}

\author{
Ratihana Nurul Indias*, Rurie Ratna Shantiningsih*, Rini Widyaningrum*, Munakhir Mudjosemedi** \\ *Program Studi Pendidikan Dokter Gigi, Fakultas Kedokteran Gigi, Universitas Gadjah Mada, Yogyakarta, Indonesia \\ ${ }^{* *}$ Departemen Radiologi Dentomaksilofasial, Fakultas Kedokteran Gigi, Universitas Gadjah Mada, Yogyakarta, Indonesia \\ *JI Denta No 1 Sekip Utara, Yogyakarta, Indonesia; e-mail: ratihana.nurul@mail.ugm.ac.id
}

Submisi: 13 Oktober 2016; Penerimaan: 7 Januari 2017; Publikasi online: 29 Desember 2017

\begin{abstract}
ABSTRAK
Pemeriksaan radiografi diperlukan oleh dokter gigi untuk menetapkan diagnosis, rencana perawatan, prognosis, dan evaluasi hasil perawatan. Radiograf yang memiliki ketepatan dimensi anatomi diperlukan pada tindakan bedah dan pemasangan implan. Informasi mengenai distorsi hasil pengukuran pada radiograf diperlukan untuk mencegah kesalahan penetapan diagnosis dan rencana perawatan. Penelitian ini bertujuan untuk mengetahui perbandingan jarak metal marker pada pengukuran horizontal, vertikal, dan oblique citra Cone Beam Computed Tomography (CBCT) dengan objek sesungguhnya pada preparat mandibula kering. Sampel penelitian berupa 40 citra CBCT preparat mandibula kering yang dihasilkan oleh mesin Volux 3D dental CT (Genoray, Korea) dengan menggunakan tegangan $60 \mathrm{kVp}$, kuat arus $60 \mathrm{mAs}$, dan waktu paparan 10 detik. Pengukuran pada citra CBCT dilakukan dengan mengukur jarak terjauh antara kedua metalmarker secara horizontal, vertikal, dan oblique menggunakan software Volux 3D dental CT (GDP-1 software Triana). Hasil pengukuran pada citra CBCT dibandingkan dengan hasil pengukuran pada preparat mandibula dan dianalisis dengan menggunakan wilcoxon signed rank test. Distorsi dihitung dari perubahan hasil pengukuran pada citra CBCT dibagi dengan ukuran sesungguhnya pada objek, dan dinyatakan dalam satuan persen (\%). Hasil penelitian menunjukkan adanya perbedaan yang bermakna $(p<0,05)$ antara hasil pengukuran jarak metal marker pada citra CBCT dibandingkan dengan objek sesungguhnya pada preparat mandibula kering, kecuali hasil pengukuran oblique tanpa melibatkan basis mandibula di bagian anterior mandibula. Rerata distorsi tertinggi pada citra CBCT panoramic view sebesar $8 \%$, dengan nilai distorsi yang berbeda pada setiap bagian mandibula.
\end{abstract}

Kata kunci: Cone Beam Computed Tomography (CBCT); mandibula; metal marker, pengukuran

\begin{abstract}
The distance comparison of Cone Beam Computed Tomography (CBCT) image with the real object. Dentist use radiographs to establish diagnosis, treatment plan, prognosis, as well as to evaluate patient's treatment. Accurate anatomical dimension is a pivotal point in radiography, especially in the field of oral surgery and dental implant planning. The information about distortion in radiograph is very important to prevent any misdiagnosis and incorrect treatment plan. The purpose of this study was to compare the metal marker distance in CBCT image with the real measurement in dried mandibles. Samples in this study were 40 CBCT images of human dried mandibles, which were produced by using Volux 3D dental CT (Genoray, Korea, $60 \mathrm{kVp}, 60 \mathrm{mAs}$, 10s). Horizontal, vertical, and oblique measurements on CBCT image were done by using Volux 3D dental CT software (GDP-1 software Triana). The measurement on $C B C T$ image was compared with the real measurement by using Wilcoxon signed rank test. Image distortion was calculated by subtracting the metal marker distance obtained from CBCT images by the real distance obtained by a direct measurement on dried mandible. The distortion was expressed as a percentage. There were some significant differences $(p<0.05)$ between metal marker distance on CBCT image with a direct measurement in dried mandibles, except oblique measurements on anterior mandibular body that was done without involving mandibular base. The maximal distortion on panoramic view of CBCT image in this study was $8 \%$, and the distortion was different in each part of the mandible.
\end{abstract}

Keywords: Cone Beam Computed Tomography (CBCT); mandible; metal marker; measurement

\section{PENDAHULUAN}

Pemeriksaan radiografi berperan penting pada evaluasi dan perawatan di bidang kedokteran gigi karena radiograf menyampaikan informasi kondisi objek yang tidak dapat dilihat secara klinis.
Radiograf diperlukan untuk menentukan diagnosis, rencana perawatan, prosedur perawatan, prognosis, follow-up, dan edukasi bagi pasien. ${ }^{1}$ Dokter gigi membutuhkan kualitas citra radiograf yang optimal dengan resolusi tinggi dan detail 
sangat rinci agar dapat menetapkan diagnosis secara benar, khususnya pada perawatan yang memerlukan ketelitian seperti pada pemasangan implan yang membutuhkan ketepatan dimensi anatomi. ${ }^{2}$ Distorsi pada radiograf adalah perubahan ukuran citra objek pada radiograf dibandingkan dengan ukuran sesungguhnya pada objek. ${ }^{3}$ Distorsi dapat terjadi karena angulasi sinar X, posisi objek, dan posisi reseptor yang kurang tepat. ${ }^{4}$ Distorsi pada radiograf dapat menyebabkan permasalahan pada proses diagnosis. ${ }^{5}$

Mesin Cone Beam Computed Tomography $(C B C T)$ merupakan alat radiografi yang menghasilkan citra yang informatif dan menggambarkan struktur kraniofasial, meliputi struktur anatomi rongga mulut, wajah, dan rahang pasien. Penelitian terdahulu menunjukkan bahwa rata-rata hasil pengukuran pada citra CBCT tidak berbeda signifikan dengan objek sesungguhnya. ${ }^{6}$ Salah satu ciri-ciri radiograf yang ideal adalah memberikan informasi dengan bentuk dan ukuran yang sama seperti objek yang dicitrakan. Radiograf yang akurat mencitrakan struktur anatomis tepat seperti penampakan objek yang sesungguhnya. Oleh karena itu besaran distorsi dari sebuah citra radiografi perlu diketahui, baik pada pengukuran secara horizontal, vertikal, maupun oblique. ${ }^{7}$ Penelitian ini bertujuan untuk mengetahui perbandingan jarak metal markerpada pengukuran horizontal, vertikal, dan oblique citra CBCT dibandingkan dengan objek sesungguhnya pada preparat mandibula kering.

\section{METODE PENELITIAN}

Penelitian observasional analitik ini merupakan kelanjutan dari penelitian sebelumnya. ${ }^{8}$ Ethical clearance diperoleh dari Komisi Etik Penelitian FKG UGM No. 00202/KKEP/FKG-UGM/EC/2015. Empat puluh preparat mandibula kering digunakan sebagai sampel pada penelitian ini. Setiap preparat mandibula yang telah dilengkapi dengan metal marker diukur menggunakan jangka sorong digital Krisbow $^{\otimes}$ ketelitian $0,01 \mathrm{~mm}$ dengan menghubungkan titik terjauh antar metal marker. Preparat mandibula dicitrakan menggunakan mesin Volux 3D dental CT (Genoray, Korea) yang diatur dengan rincian paparan $60 \mathrm{kVp}$ dan $60 \mathrm{mAs}$ selama 10 detik.

Pengukuran pada citra CBCT dilakukan dengan menghubungkan metal marker yang tercitrakan pada layar monitor menggunakan GDP1 software Triana dengan pedoman sesuai Gambar 1. Pengaturan slice interval $0,5 \mathrm{~mm}$ dan slice thickness $0,5 \mathrm{~mm}$; Axial section pada panoramic view diletakkan pada puncak tulang alveolar sebelah mesial 37 atau 47; Sembilan titik untuk pengaturan lengkung gigi ditempatkan di antara gigi 31,41 , sebelah distal gigi $32,42,33,43,35$, 45, 37 dan gigi 47. Jika preparat mandibula tidak memiliki gigi lengkap maka dilakukan penyesuaian dengan memperkirakan letak gigi yang telah hilang. Masing-masing titik tersebut diletakkan di pertengahan jarak permukaan bukal-lingual sepanjang lengkung gigi.

Pengukuran pada citra CBCT dilakukan secara horizontal, vertikal, dan oblique pada panoramic view. Selain itu, pengukuran secara vertikal di midline rahang bawah juga dilakukan pada cross sectional view. Lokasi dan kode pengukuran sesuai dengan Gambar 2 dan Gambar 3.

Hasil pengukuran kemudian diuji normalitas Shapiro-Wilk untuk mengetahui distribusi data semua kelompok. Hasil uji Shapiro-Wilk menunjukkan terdapat variabel data yang berdistribusi tidak normal, sehingga data pada penelitian ini diuji dengan wilcoxon signed rank test.

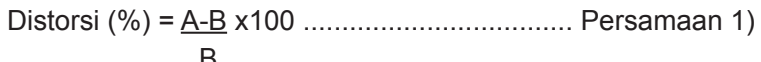

Keterangan: A. Ukuran pada citra CBCT; B. Ukuran pada objek sesungguhnya

Distorsi citra dihitung dengan cara perubahan ukuran objek pada citra CBCT dibagi dengan ukuran sesungguhnya pada objek kemudian dikalikan 100 dan dinyatakan dalam satuan persen $(\%)$, sesuai dengan persamaan 1 . Nilai negatif akan menunjukkan ukuran pada citra lebih kecil dari ukuran sesungguhnya atau dengan kata lain terjadi pengecilan ukuran pada citra, dan sebaliknya nilai distorsi positif menunjukkan citra yang lebih besar dibandingkan objek sesungguhnya. 


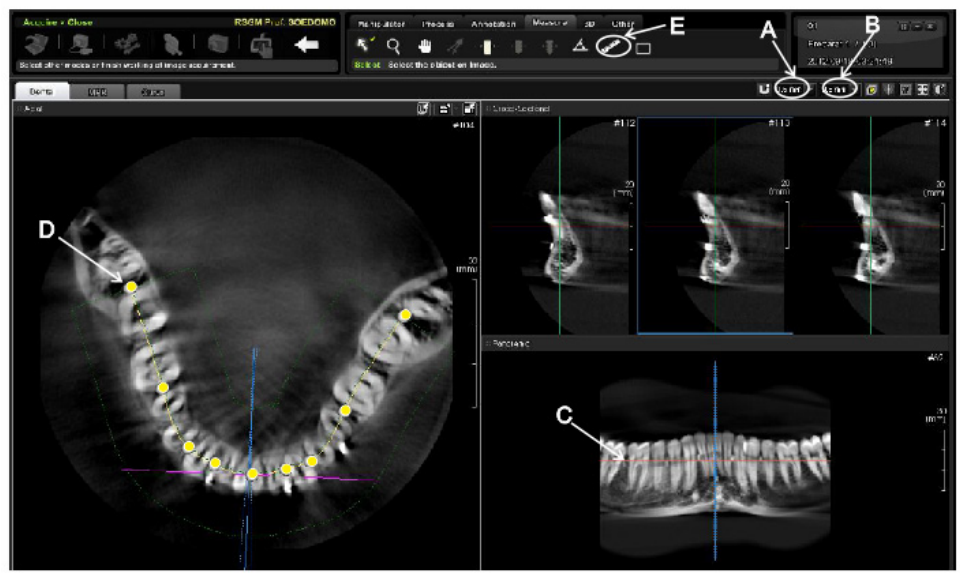

Gambar 1. Pengaturan citra $\mathrm{CBCT}$ sebelum dilakukan pengukuran jarak metal marker. (A) Pengaturan slice interval; (B) Pengaturan slice thickness; (C) Pengaturan axial section; (D) Titik-titik pengaturan lengkung gigi; (E) Icon distance untuk mengukur jarak.

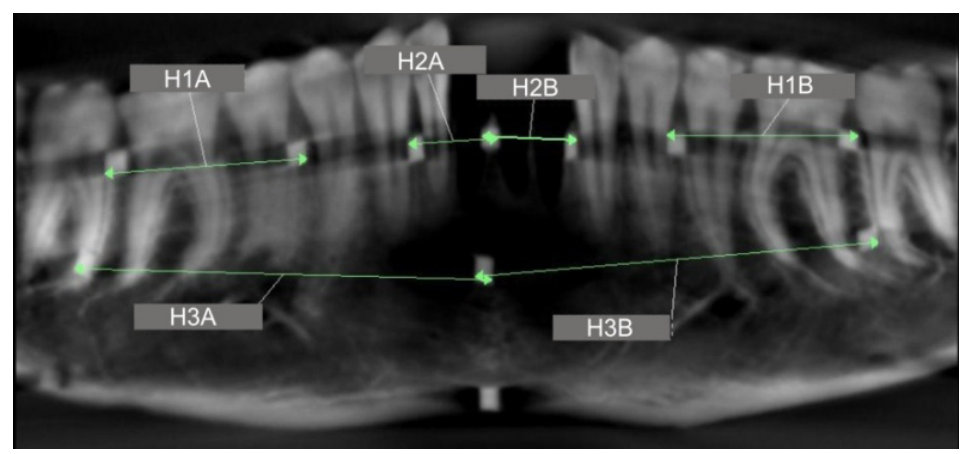

Gambar 2. Pengukuran secara horizontal citra $\mathrm{CBCT}$ pada panoramic view. H1A, H1B, H2A, H2B, H3A, dan H3B adalah kode pengukuran horizontal.

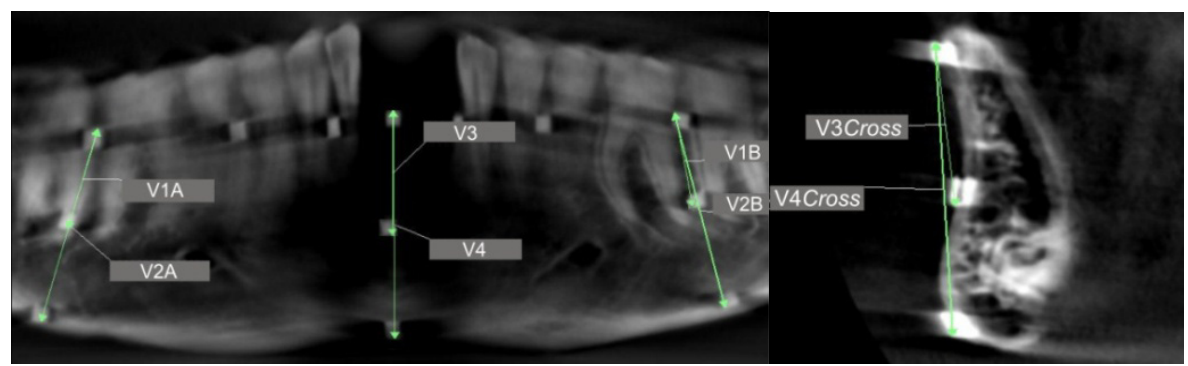

(A)

(B)

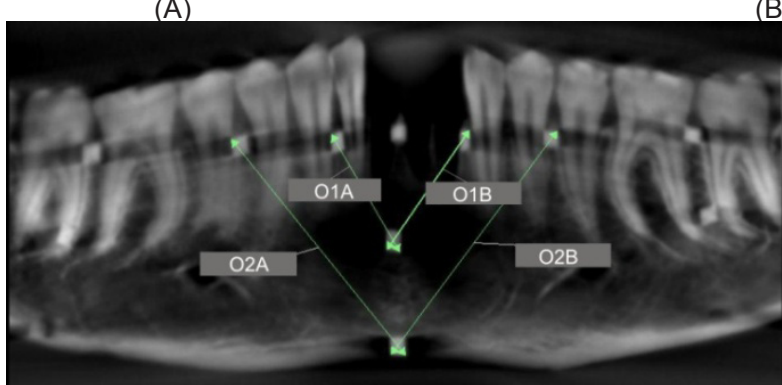

(C)

Gambar 3. Pengukuran secara vertikal citra CBCT pada: panoramic view (A); cross sectional view (B); Pengukuran secara oblique citra CBCT pada panoramic view (C); V. Kode pengukuran vertikal; O. Kode pengukuran oblique. 


\section{HASIL PENELITIAN}

Sebagian besar data hasil pengukuran memiliki distribusinormal $(p>0,05)$, kecuali variabel pengukuran H1B dan H2B. Rerata distorsi dan data hasil uji hipotesis (wilcoxon signed rank test) dirangkum pada Tabel 1. Hasil penelitian ini menunjukkan bahwa pada pengukuran horizontal di sekitar akar gigi-geligi posterior (H1B \& H1A) terdapat kecenderungan perbesaran ukuran pada citra sebesar $5 \%$ dan $8 \%$. Adapun pengukuran vertikal di area akar gigi-geligi posterior (V1B \& V1A) justru menunjukkan pengecilan sebesar $2 \%$ dan $4 \%$. Sementara pada pengukuran vertikal yang melibatkan basis mandibula (V2A \& V2B), terlihat adanya perbesaran ukuran sebesar $5 \%$ dan $6 \%$. Hasil penelitian ini menunjukkan kesesuaian dengan hasil penelitian sebelumnya. ${ }^{9}$

\section{PEMBAHASAN}

Penelitian terdahulu ${ }^{9}$ menunjukkan rerata distorsi citra CBCT pada pengukuran vertikal dan horizontal di area molar pertama dan molar kedua menggunakan preparat mandibula kering pada cross sectional view sebesar $4,7 \%$. Rerata distorsi geometri sebesar $0,1-5,2 \%$ pada pengukuran vertikal di sepanjang mandibula menggunakan cross sectional view. Jika dibandingkan dengan penelitian ${ }^{9}$ tersebut, maka hasil penelitian ini menunjukkan rerata distorsi geometri yang lebih besar. Secara umum pada penelitian ini rerata distorsi untuk pengukuran vertikal sebesar $2-8 \%$, sedangkan pengukuran horizontal sebesar $-6 \%$ hingga $8 \%$ dan pengukuran oblique sebesar $0-6 \%$. Sedikit berbeda dengan penelitian sebelumnya, ${ }^{9}$

Tabel 1. Rerata, standar deviasi (SD) distorsi dan hasil uji hipotesis

\begin{tabular}{|c|c|c|c|c|c|}
\hline Kode pengukuran & $\begin{array}{c}\text { Kode } \\
\text { kelompok }\end{array}$ & Kelompok & $\begin{array}{c}\text { Perbedaan rerata (Rerata } \\
\mathrm{A}-\mathrm{B}) \pm \mathrm{SD} \\
(\mathrm{mm})\end{array}$ & $\begin{array}{c}\text { Rerata distorsi } \\
\text { [Rerata dari }(\mathrm{A}-\mathrm{B}) \times 100 / \mathrm{B}] \\
\pm \mathrm{SD}\end{array}$ & p uji hipotesis \\
\hline \multicolumn{6}{|l|}{ Posterior } \\
\hline \multirow{2}{*}{ H1A } & $A$ & CBCT & $1,66 \pm 0,578$ & $8 \% \pm 3 \%$ & $0,000^{*}$ \\
\hline & $\mathrm{B}$ & Preparat & & & \\
\hline \multirow{2}{*}{ H1B } & $A$ & СВСТ & $0,94 \pm 0,901$ & $5 \% \pm 5 \%$ & $0,000^{*}$ \\
\hline & $B$ & Preparat & & & \\
\hline \multirow{2}{*}{ V1A } & $A$ & СBCT & $-0,53 \pm 0,771$ & $-4 \% \pm 6 \%$ & $0,000^{*}$ \\
\hline & $\mathrm{B}$ & Preparat & & & \\
\hline \multirow{2}{*}{ V1B } & $A$ & $\mathrm{CBCT}$ & $-0,28 \pm 0,755$ & $-2 \% \pm 6 \%$ & 0,068 \\
\hline & $B$ & Preparat & & & \\
\hline \multirow{2}{*}{ V2A } & $A$ & CBCT & $1,07 \pm 0,528$ & $5 \% \pm 2 \%$ & $0,000^{*}$ \\
\hline & $\mathrm{B}$ & Preparat & & & \\
\hline \multirow{2}{*}{ V2B } & $A$ & СВСТ & $1,24 \pm 0,488$ & $6 \% \pm 2 \%$ & $0,000^{*}$ \\
\hline & B & Preparat & & & \\
\hline \multicolumn{6}{|l|}{ Anterior } \\
\hline \multirow{2}{*}{ H2A } & $A$ & $\mathrm{CBCT}$ & $-0,45 \pm 0,762$ & $-4 \% \pm 7 \%$ & $0,000^{*}$ \\
\hline & $B$ & Preparat & & & \\
\hline \multirow{2}{*}{ H2B } & $A$ & CBCT & $-0,68 \pm 0,695$ & $-6 \% \pm 6 \%$ & $0,000^{*}$ \\
\hline & B & Preparat & & & \\
\hline \multirow{2}{*}{ V3 } & $A$ & СBCT & $0,79 \pm 0,515$ & $6 \% \pm 4 \%$ & $0,000^{*}$ \\
\hline & $B$ & Preparat & & & \\
\hline \multirow{2}{*}{ V4 } & $A$ & СBCT & $1,63 \pm 0,547$ & $7 \% \pm 2 \%$ & $0,000^{*}$ \\
\hline & B & Preparat & & & \\
\hline \multirow{2}{*}{ V3Cross } & A & CBCT Cross & $1,03 \pm 0,328$ & $8 \% \pm 3 \%$ & $0,000^{*}$ \\
\hline & $B$ & Preparat & & & \\
\hline \multirow{2}{*}{ V4Cross } & A & CBCT Cross & $1,96 \pm 0,458$ & $8 \% \pm 1 \%$ & $0,000^{*}$ \\
\hline & B & Preparat & & & \\
\hline \multirow{2}{*}{ 01A } & $A$ & СBCT & $0,13 \pm 0,581$ & $1 \% \pm 3 \%$ & 0.180 \\
\hline & B & Preparat & & & \\
\hline \multirow{2}{*}{ 01B } & $A$ & СВСТ & $-0,01 \pm 0,424$ & $0 \% \pm 2 \%$ & 0,791 \\
\hline & B & Preparat & & & \\
\hline \multicolumn{6}{|l|}{ Posterior-anterior } \\
\hline \multirow{2}{*}{ H3A } & A & СBCT & $3,38 \pm 2,145$ & $7 \% \pm 5 \%$ & $0,000^{*}$ \\
\hline & B & Preparat & & & \\
\hline \multirow{2}{*}{ Н3В } & A & СВCT & $1,71 \pm 2,210$ & $4 \% \pm 5 \%$ & $0,000^{*}$ \\
\hline & $\mathrm{B}$ & Preparat & & & \\
\hline O2A & $\begin{array}{l}A \\
B\end{array}$ & $\begin{array}{c}\text { СВСТ } \\
\text { Preparat }\end{array}$ & $1,95 \pm 1,726$ & $6 \% \pm 5 \%$ & $0,000^{*}$ \\
\hline O2B & $\begin{array}{l}A \\
B\end{array}$ & $\begin{array}{c}\text { CBCT } \\
\text { Preparat }\end{array}$ & $1,15 \pm 1,206$ & $3 \% \pm 4 \%$ & $0,000^{*}$ \\
\hline
\end{tabular}

Keterangan: H: horizontal; V: vertikal; O: oblique; SD: standart deviation; *: signifikan $(p<0,05)$ 
penelitian ini hanya menggunakan cross sectional view pada pengukuran area midline mandibula (V3Cross \& V4Cross). Perbedaan rerata distorsi tersebut diduga terjadi karena penelitian ini menggunakan mesin CBCT yang berbeda dengan penelitian sebelumnya. ${ }^{9}$ Berbagai merk mesin CBCT yang memiliki pengaturan pencitraan yang bervariasi akan menunjukkan hasil pengukuran yang berbeda pula. ${ }^{9}$

Hasil penelitian ini menunjukkan distorsi jarak metal marker pada citra CBCT terhadap jarak pada preparat mandibula sebesar 0-8\% dengan perbedaan rerata 0,01-3,38 mm. Hasil ini menunjukkan perbedaan yang bermakna secara statistik hampir pada sebagian besar variabel pengukuran. Perbedaan yang bermakna secara statistik ditemukan pula pada penelitian sebelumnya. ${ }^{2,10,11}$ Pengukuran V1B, O1A, dan O1B pada penelitian ini tidak menunjukkan perbedaan yang bermakna dibandingkan dengan hasil pengukuran yang sesungguhnya pada preparat mandibula. Perbedaan yang tidak bermakna secara statistik ditemukan pula pada beberapa penelitian sebelumnya. ${ }^{6,12}$

Jenis mesin radiografi yang diproduksi oleh pabrik yang berbeda memiliki indeks distorsi yang berbeda-beda. Hal tersebut disebabkan karena setiap mesin sinar $\mathrm{X}$ memiliki spesifikasi yang tidak sama, sehingga distorsi suatu mesin hanya spesifik untuk mesin sinar $\mathrm{X}$ tersebut. Pernyataan tersebut didukung oleh hasil penelitian yang menunjukkan angka distorsi geometri yang bervariasi pada berbagai mesin CBCT yang diujinya. ${ }^{13}$ Perlu diperhatikan pula bahwa selain memiliki spesifikasi mesin yang berbeda, berbagai mesin CBCT juga memiliki resolusi citra yang berbeda-beda. ${ }^{9}$ Jenis scanner sinar $\mathrm{X}$ dan pengaturan rekonstruksi juga dapat mempengaruhi kualitas citra CBCT. ${ }^{13}$ Radiograf dengan resolusi dan kualitas citra yang baik menunjukkan kesalahan pengukuran yang minimal pada citra radiografinya. ${ }^{9}$

Penggunaan bahan metal sebagai marker pengukuran tidak mempengaruhi distorsi ukuran pada citra СВCT karena hampir tidak ada perbedaan antara hasil pengukuran pada citra CBCT dengan ukuran sebenarnya. ${ }^{6,12}$ Namun demikian, artefak akibat adanya metal yang disertai dengan resolusi citra yang rendah dan ketidakteraturan bentuk tulang dicurigai dapat mempengaruhi akurasi pengukuran karena hal-hal tersebut dapat mempersulit identifikasi titik acuan dalam pengukuran pada citra CBCT. ${ }^{14}$ Struktur anatomi pada citra CBCT tanpa adanya artefak bahan metal lebih mudah diidentifikasi karena keberadaan artefak bahan metal dapat membuat struktur tulang kurang tercitrakan dengan jelas. ${ }^{15}$

Penelitian ini menggunakan tembaga sebagai marker pengukuran. ${ }^{8}$ Penggunaan marker radiopak membantu identifikasi titik acuan pada saat pengukuran, meskipun bahan dengan densitas tinggi dapat menyebabkan adanya artefak menyerupai bentuk bintang pada citra CBCT. ${ }^{16}$ Artefak tersebut juga tampak pada penelitian ini sehingga sedikit mempersulit penentuan titik acuan pengukuran. Gambaran artefak akibat adanya metal ini disebut 'halo effect' dan membuat beberapa metal marker tercitrakan hampir 2 kali lebih besar dari ukuran yang sebenarnya. Penggunaan marker bentuk bulat dengan ukuran yang seragam dan titik tengah marker dengan densitas paling tinggi sebagai acuan pengukuran dapat meminimalkan kesalahan pengukuran pada citra CBCT akibat 'halo effect' tersebut. ${ }^{17}$ Pengukuran pada penelitian ini dilakukan menggunakan titik terjauh antarmarker sebagai acuan sehingga jika terjadi perubahan ukuran marker pada citra CBCT diduga dapat mempengaruhi hasil pengukuran. Ukuran marker pada penelitian ini tidak diseragamkan dan tidak ada data terkait ukuran marker yang digunakan pada setiap preparat, sehingga tidak dapat diketahui ada tidaknya perubahan ukuran marker pada citra CBCT.

Lokasi pengukuran mempengaruhi akurasi pengukuran linear pada citra CBCT. Hasil penelitian terdahulu menunjukkan distorsi pada pengukuran vertikal sebesar $2-51 \%$. Oleh karena itu penempatan objek perlu diperhatikan, karena posisi objek dapat menjadi faktor pengganggu yang mampu mempengaruhi besaran distorsi suatu penelitian. ${ }^{18}$ Pada penelitian ini diyakini bahwa penempatan objek telah dikendalikan dengan sinar bantu yang berasal dari mesin CBCT. Penempatan preparat mandibula pada holder juga diseragamkan 
dengan memposisikan ramus mandibula tegak lurus dengan bidang horizontal.

Hingga saat ini belum ada batasan nilai distorsi radiografi yang dianggap normal. Perbedaan ukuran objek kurang dari $1 \mathrm{~mm}$ pada citra radiografi tidak akan berdampak secara klinis dalam tindakan pemasangan implan. ${ }^{6}$ Dampak klinis distorsi citra СВCT ditentukan oleh rasio perbedaan ukuran pada citra terhadap ukuran keseluruhannya yang disebut indeks distorsi. Rerata distorsi pada penelitian ini untuk pengukuran vertikal sebesar $2-8 \%$, sedangkan pengukuran horizontal sebesar $-6 \%$ hingga $8 \%$, pengukuran oblique sebesar $0-6 \%$, serta pada cross sectional view sebesar $8 \%$. Perbedaan ukuran kurang dari $0,1 \mathrm{~mm}$ pada pengukuran yang lebih besar seperti pada bidang ortodontik tidak akan berdampak klinis. Namun demikian, jika pengukuran dilakukan pada objek dengan skala lebih kecil, perbedaan ukuran tersebut dapat berdampak secara klinis. Oleh karena itu, jika ditemukan distorsi yang cukup besar lebih baik dilakukan kalibrasi terhadap mesin CBCT. Selanjutnya klinisi juga perlu melakukan kalibrasi dengan indeks distorsi pada saat mengukur objek pada citra CВCT. Kalibrasi dengan indeks distorsi tersebut dapat meningkatkan akurasi ukuran pada citra CBCT.

Analisis pada citra radiografi membantu klinisi dalam mengukur besar lesi dan mengukur tinggi tulang alveolar sebelum dilakukan pemasangan implan. Selain itu, ketebalan tulang yang diukur pada citra radiografi dapat mempengaruhi rencana perawatan pada pemasangan implan. Lebar tulang rahang yang terbatas memerlukan tindakan perbesaran tulang atau bone augmentation, namun tulang rahang dengan ketebalan minimal $4 \mathrm{~mm}$ tidak memerlukan tindakan tersebut. ${ }^{2}$ Perbesaran ukuran pada citra radiografi di area kondilus mandibular dapat salah diartikan sebagai hiperplasia kondilus. Hal tersebut menunjukkan bahwa analisis kuantitatif pada citra radiografi berperan penting pada bidang kedokteran gigi. Distorsi ukuran pada masing-masing mesin $\mathrm{CBCT}$ penting diketahui oleh klinisi sebelum dilakukan analisis terhadap citra CBCT. ${ }^{4}$ Hasil penelitian ini memberikan nilai distorsi yang spesifik untuk mesin CBCT yang digunakan pada penelitian ini, yaitu Volux $3 D$ dental $C T$ (Genoray, Korea) yang terbatas pada panoramic view, informasi distorsi citra pada cross sectional view hanya pada pengukuran area anterior rahang bawah. Citra CBCT merupakan alat penunjang pemeriksaan yang dapat diandalkan, terlebih dengan mengkalibrasi ukuran pada citra terhadap indeks distorsi dari mesin yang digunakan.

\section{KESIMPULAN}

Dari hasil penelitian dapat disimpulkan bahwa terdapat perbedaan yang bermakna antara hasil pengukuran jarak metal marker pada citra CBCT panoramic view dibandingkan dengan hasil pengukuran objek sesungguhnya pada preparat mandibula kering dengan besaran ditorsi berbeda-beda pada setiap regio, kecuali pada hasil pengukuran oblique tanpa melibatkan basis mandibula di bagian anterior mandibular tidak menunjukkan perbedaan yang bermakna.

Dari penelitian ini disarankan beberapa hal yaitu pengukuran menggunakan panoramic view pada citra CBCT Volux (Genoray, Korea) diperlukan kalibrasi sebesar 2-8\% untuk pengukuran vertikal, sedangkan pengukuran horizontal sebesar $-6 \%$ hingga $8 \%$, pengukuran oblique sebesar $0-6 \%$ dan pada cross sectional view sebesar $8 \%$. Diperlukan penelitian lebih lanjut untuk mengetahui faktorfaktor yang mempengaruhi distorsi geometri pada citra $\mathrm{CBCT}$ dan penelitian lebih lanjut mengenai distorsi citra CBCT pada area TMJ dan rahang atas.

\section{DAFTAR PUSTAKA}

1. Basrani B. Endodontic radiology, $2^{\text {nd }}$ ed. Wiley \& Sons, Inc. Oxford; 2012. 193.

2. Loubele M, Eugenia GM, Jacobs R, Suetens $P$, Steenberghe D. A comparison of jaw dimensional and quality assessments of bone characteristics with cone-beam ct, spiral tomography, and multi-slice spiral CT. Int. J. Oral Max. Impl. 2007; 22(3): 446 - 454.

3. White SC, Pharoah MJ. Oral radiology principles and interpretation. $6^{\text {th }}$ ed. Elsevier. China; 2009. 46, 78, 109, 175, 256, 600, 602. 
4. Iannucci JM, Howerton LJ. Dental radiography: principles and techniques, $4^{\text {th }}$ ed. Elsevier. USA; 2012. 83, 111 - 112, 313 - 321.

5. Froum SJ. Dental implant complications $1^{\text {st }}$ ed. Wiley-Blackwell. Oxford; 2010. 98 - 99.

6. Izzati L, Rahman S, Alam MK, Daud F. Validity of Cone Beam Computed Tomography (CBCT) on estimation of implant fixture length. Int. Med. J. 2013; 20(3): 355 - 358.

7. Karjodkar FR. Textbook of dental and maxillofacial radiology. Jaypee. New Delhi. 2006; 66, 75, 227.

8. Mudjosemedi M, Widyaningrum R, Gracea RS. Perbedaan hasil pengukuran tulang mandibula pada radiograf panoramik dan 3D Dental CT, Laporan Penelitian. Fakultas Kedokteran Gigi Universitas Gadjah Mada. Yogyakarta. 2012; 1 - 49.

9. Suomalainen $A$, Vehmas $T$, Kortesniemi $M$, Robinson S, Peltola J. Accuracy of linear measurements using dental cone beam and conventional multislice computed tomography. Dentomaxillofac. Rad. 2008; (37): 10 - 17.

10. Pinsky HM, Dyda S, Pinsky RW, Misch KA, Sarment DP. Accuracy of three-dimensional measurements using cone-beam CT. Dentomaxillofac. Rad. 2006; (35): 10 - 416.

11. Sakabe J, Kuroki Y, Fujimaki S, Nakajima I, Honda K. Reproducibility and accuracy of measuring unerupted teeth using limited cone beam X-ray CT. Dentomaxillofac. Rad. 2007; 36: $2-6$.

12. Lagravère MO, Carey J, Toogood RW, Majord PW. Three-dimensional accuracy of measurements made with software on conebeam computed tomography images. Am. J. Orthod. Dentofacial Orthop. 2008; (34): $112-116$.
13. Loubele M, Jacobs R, Maes F, Denis K, White S, Coudyzer W, Lambrichts I, Steenberghe D, Suetens P. Image quality VS radiation dose of four cone beam computed tomography scanners. Dentomaxillofac. Rad. 2008; 37: $309-318$.

14. Mangione F, Meleo D, Talocco M, Pecci R, Pacifici L, Bedini R. Comparative evaluation of the accuracy of linear measurements between cone beam computed tomography and 3D microtomography. Ann Ist Super Sanità. 2013; 49(3): $261-265$.

15. Cremonini CC, Dumas M, Pannuti CM, Neto JB, Cavalcanti MG, Lima LA. Assessment of linear measurements of bone for implant sites in the presence of metallic artefacts using cone beam computed tomography and multislice computed tomography. Int. J. Oral Maxillofac. Surg. 2011; 40(8): $845-850$.

16. Whaites E. Essential of dental radiography and radiology $5^{\text {th }}$ ed. Elsevier. China; 2013. 3: 193 - 195, $206-207$.

17. Ballrick JW, Palomo JM, Ruch E, Amberman BD, Hanse MG. Image distortion and spatial resolution of a commercially available conebeam computed tomography machine. Am. J. Orthod. Dentofacial. 2008; 134: 573 - 582.

18. Sforza NM, Franchini F, Lamma A, Botticelli S, Ghigi G. Accuracy of computerized tomography for the evaluation of mandibular sites prior to implant placement. Int. J. Periodont. Rest. 2007; 27(6): 589 - 595. 